\title{
Drug-Induced Liver Injury Due To Losartan
}

\author{
Joana Diogo, Rita Monteiro, Carolina Coelho, Angela Ghiletchi, Rodrigo Leão, Conceição Loureiro \\ Centro Hospitalar Universitário Lisboa Central, Lisbon, Portugal
}

\section{Doi: 10.12890/2021_002856 - European Journal of Case Reports in Internal Medicine - ๑ EFIM 2021}

Received: 31/08/2021

Accepted: 21/10/2021

Published: 25/11/2021

How to cite this article: Diogo J, Monteiro R, Coelho C, Ghiletchi A, Leão R, Loureiro C. Drug-induced liver injury due to losartan. EJCRIM 2021;8: doi:10.12890/2021_002856.

Conflicts of Interests: The authors declare there are no competing interests.

This article is licensed under a Commons Attribution Non-Commercial 4.0 License

\section{ABSTRACT}

Drug-induced liver injury (DILI) is a challenging diagnosis since a wide variety of medicines can cause adverse reactions. Losartan is an angiotensin II receptor antagonist (ARA-II) approved for the treatment of arterial hypertension. The most common adverse effects are fatigue, anaemia, weakness and cough. An increase in transaminases has been reported with less frequency ( $<2 \%$ of cases). Although the mechanism is not fully understood, DILI onset is usually within 1-8 weeks of therapy, and hepatic enzymology usually normalizes 2-4 months after drug suspension. The authors present the case of a 66-year-old male patient with a medical history of arterial hypertension and a prior hospitalization (4 years previously) for drug-induced hepatitis, which, at the time, was attributed to a dietary supplement. Four years later, because of new onset of hypertension, losartan was reintroduced. After 3 weeks, the patient was admitted to the emergency department with complaints of acute abdominal pain associated with asthenia, nausea and increased abdominal volume that had first developed 8 days previously. After exclusion of other causes, DILI associated with losartan was assumed. This is a very rare adverse effect since only seven cases have been described in the literature.

\section{LEARNING POINTS}

- Toxic hepatitis due to losartan is very rare, despite widespread use of the drug.

- A high index of suspicion for drug-induced liver injury (DILI) should be maintained while other diagnoses are carefully excluded.

- Monitoring the use of the offending drug is crucial, since DILI recurrence is associated with worse prognosis.

\section{KEYWORDS}

Losartan, drug-induced liver injury

\section{INTRODUCTION}

Drug-induced liver injury (DILI) has an incidence of $10-15$ cases per 100,000 population/year. It is an important cause of acute liver injury, which is included in the differential diagnosis of acute hepatitis ${ }^{[1]}$. Some drugs are well known to cause acute liver injury, especially following an overdose. Losartan is a well-tolerated drug with few significant adverse effects, the most common of which are dry cough, hyperkalaemia and gastrointestinal effects ${ }^{[2]}$. Although uncommon, a transient elevation in hepatic transaminases can occur in $<2 \%$ of patients. Seven cases of hepatitis due to losartan are described in the literature ${ }^{[3]}$.

\section{CASE DESCRIPTION}

We report the case of a 66-year-old Caucasian man with a medical history of hypertension, treated with a single 50 mg dose of losartan daily for the previous 3 weeks. The patient had been hospitalized 4 years previously for DILI, which was attributed at the time to a dietary supplement. During the first hospitalization, an exhaustive study excluded consumption of alcohol or herbs, toxins, and infectious, 
autoimmune, tumoural and hereditary causes. Both losartan and the supplement were suspended, with the latter assumed to be the main culprit because of a more likely established association.

Two weeks after losartan reintroduction, the patient began to complain of acute abdominal pain, nausea, vomiting and, after 1 week, developed icteric skin and choluria. Physical examination was notable for skin and sclerotic jaundice, hepatomegaly with slightly painful palpation and no signs of encephalopathy. Blood tests revealed AST 2522 IU/I, ALT 3603 IU/I and ALP 184 IU/I, GGT 375 IU/I, INR 1.65, thrombocytopenia 101,000 and hyperbilirubinemia with total bilirubin $5.28 \mathrm{mg} / \mathrm{dl}$ and direct bilirubin $3.23 \mathrm{mg} / \mathrm{dl}$. Viral serologies for hepatitis A, B, C and E, and HIV 1 and 2 were negative, and abdominal ultrasound was normal. Autoimmune hepatitis (AIH) was excluded with tests for anti-nuclear, anti-mitochondrial, anti-smooth muscle, anti-neutrophil cytoplasm PR3 and MPO, with SLA/LP being negative, resulting in a Simplified AlH score of 1. Infectious and infiltrative diseases were excluded. Angiography excluded portal system thrombosis and ischaemic lesions. For the first 6 days after losartan suspension, the patient showed poor evolution with increased blood concentrations of AST (3055 IU/I), ALT (4315 IU/I), GGT (524 IU/I), ALP (171 IU/I) and bilirubin (19.23 mg/dl). We then opted to start prednisolone $1 \mathrm{mg} / \mathrm{kg} /$ day, after which the patient progressively improved (Table 1).

\begin{tabular}{|c|c|c|c|c|c|c|c|c|c|c|c|}
\hline & Day 1 & Day 3 & Day 5 & Day 6 & Day 8 & Day 9 & Day 10 & Day 14 & Day 15 & Day 17 & Day 21 \\
\hline ALT (IU/I) & 3603 & 4315 & 3113 & 3539 & 2895 & 3068 & 1878 & 1306 & 1087 & 838 & 548 \\
\hline AST (IU/I) & 2522 & 3055 & 2018 & 2532 & 1408 & 801 & 581 & 405 & 335 & 230 & 165 \\
\hline ALP (IU/I) & 184 & 187 & 156 & 153 & 171 & 150 & 166 & 155 & 159 & 150 & 153 \\
\hline GGT (IU/I) & 375 & 410 & 315 & 324 & 401 & 430 & 509 & 524 & 503 & 444 & 400 \\
\hline $\begin{array}{l}\text { Total bilirubin } \\
\text { (mg/dl) }\end{array}$ & 5.28 & 10.05 & 10.26 & 14.77 & 19.23 & 15.35 & 14.92 & 18.99 & 18.26 & 17.33 & 11.42 \\
\hline $\begin{array}{l}\text { Direct bilirubin } \\
\text { (mg/dl) }\end{array}$ & 3.23 & 6.27 & 6.66 & 9.32 & 11.58 & 9.53 & 9.89 & 11.86 & 10.96 & 10.32 & 6.78 \\
\hline INR & 1.65 & 1.91 & 1.91 & 1.76 & 1.70 & 1.64 & 1.61 & 1.59 & 1.49 & 1.51 & 1.44 \\
\hline
\end{tabular}

Table 1. Evolution of hepatic enzyme, bilirubin and INR values during hospitalization

\section{DISCUSSION}

The clinical presentation of DILI is similar to that of acute hepatitis caused by other conditions ${ }^{[1]}$. It may present with anorexia, jaundice, nausea, vomiting, abdominal pain and low fever, with discrete elevation of transaminases ${ }^{[2,4]}$. DILI usually shows a hepatocellular pattern, cholestasis or both. Liver biopsy is the gold standard for diagnosis. In the clinical case described, after exclusion of other causes, there was a clear association between the initiation of losartan and improvement after its suspension ${ }^{[5]}$. Losartan-related hepatotoxicity is reported very rarely $(<0.1 \%)$, with hepatotoxicity occurring after approximately $1-8$ weeks. The hepatic lesion is mainly hepatocellular, although, less frequently, cholestasis or mixed patterns have also been described. There are 19 reported cases of toxic hepatitis due to ARA-II, of which only seven are related to losartan ${ }^{[3]}$. This is the eighth case of severe toxic hepatitis associated with losartan, with hepatocellular presentation and elevation of transaminases about 10 times above the upper limit. In two of the previous cases, transaminases were elevated around 75-100 times the upper limit of normal ${ }^{[3]}$. 


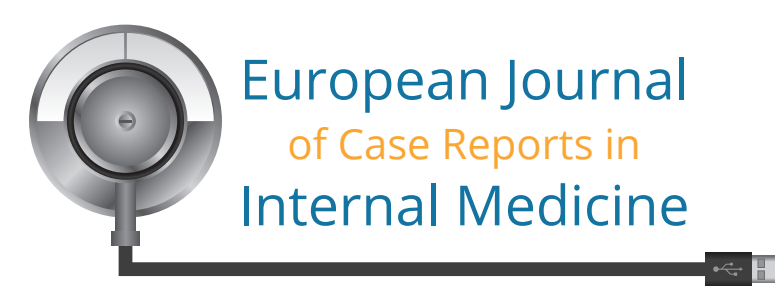

Suspending the drug is the first step in treatment. Improvement is usually seen within hours to days. In the case described, this improvement did not occur, probably because it was a second episode of DILI due to losartan, and the severity of liver damage increases with re-exposure to the offending drug.

\section{CONCLUSION}

In cases of acute hepatitis, all drugs should be investigated including ARA-II, which are widely used. Once the offending drug has been identified, it should be suspended because re-exposure can result in more severe disease.

\section{REFERENCES}

1. Fontana RJ, Seeff LB, Andrade RJ, Björnsson E, Day CP, Serrano J, et al. Standardization of nomenclature and causality assessment in drug-induced liver injury: summary of a clinical research workshop. Hepatology 2010;52:730-742. doi: 10.1002/hep.23696

2. Al-Halawani MZ, Thawabi M, Asslo F, Shaaban H, Shamoon F, Baddoura WJ. Losartan-induced ischemic hepatocellular hepatotoxicity: a case report and literature review. J Family Med Prim Care 2014;3:272-274. doi: 10.4103/2249-4863.141635

3. Ravikara P, Ankur S, Shaurva S, Taek SY, Yizhak K. Losartan-induced severe hepatic injury: a case report and literature review. Cureus 2019;11(5):e4769. doi: 10.7759/ cureus.4769

4. Tabak F, Mert A, Ozaras R, Biyikli M, Ozturk R, Ozbay G, et al. Losartan-induced hepatic injury. J Clin Gastroenterol 2002;34:585-586. doi: 10.1097/00004836-20020500000022

5. Suzuki A, Brunt EM, Kleiner DE, Miquel R, Smyrk TC, Andrade RJ, et al. The use of liver biopsy evaluation in discrimination of idiopathic autoimmune hepatitis versus druginduced liver injury. Hepatology 2011;54(3):931-939. doi: 10.1002/hep.24481 